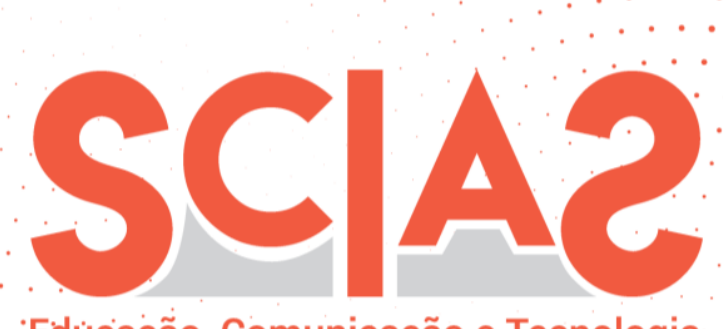

Educaçẳo, Comunicação $\mathrm{e}$ Tecnologia

Atribuição BB CY 4.0

\title{
A Educomunicação e o processo de formação dos professores: ressignificando saberes
}

Tiago Silvio Dedoné ${ }^{1}$

\section{Resumo}

Faz-se necessário direcionar pesquisas e ações de intervenção educacional, cultural e social, que permitam uma reflexão sobre ampliação de qualidade e modernização no sistema de ensino, por meio do debate e inserção de ações estratégicas educacionais que relacionem a mídia e a educação, possibilitando a formação de professores por este norte de habilitações e competências. A interface comunicação e educação é uma práxis social, uma prática de cidadania, que pode emancipar processos educacionaisivos e instigar a curiosidade e criatividade, com o uso das ferramentas e mecanismos da comunicação, além de promover a ampliação dos ecossistemas comunicacionais nos espaços educativos. Por isso, há muitos anos, teóricos de várias partes do mundo buscam apresentar novos paradigmas discursivos transversos que apontam para convergência destes campos. A Educomunicação, destaca-se como uma fonte rica de proposições, articulações de debates e norteamentos epistemológicos.

\section{Palavras-chave}

Educomunicação. Mediações Tecnológicas. Cidadania. Educação. Mídias.

Recebido em: 08/05/2019

Aprovado em: 11/09/2019

${ }^{1}$ Jornalista, Pedagogo, Especialista em Língua Portuguesa e Literatura Brasileira; Gestão e Administração Escolar; Novas Tecnologias aplicadas à Educação. Membro da Associação Brasileira de Pesquisadores e Profissionais em Educomunicação ABPEducom, Paraná, Brasil.

E-mail: tiagoassessor@hotmail.com 


\section{Introdução}

Firma-se, no contexto da contemporaneidade, uma vertente de referencial teórico que embasa a intersecção do binômio comunicação/educação, como promoção de um campo de diálogo, integração e espaços para consolidação de conhecimentos crítico, reflexivo, que buscam a emancipação de atores sociais que permeiam pelos cenários de formação. A comunicação é um componente do processo educativo. Não existe educação, sem comunicação. Enquanto essência de todo um processo de construção subjetiva, ela é elemento fundamental para a eficácia de um espaço social de construção democraticamente produtivo. "Ser dialógico é vivenciar o diálogo, é não invadir, é não manipular, é não sloganizar. O diálogo é o encontro amoroso dos homens que, mediatizados pelo mundo, o pronunciam, isto é, o transformam e, transformando-o, humanizam" (FREIRE, p.43).

A educação é entendida por Freire como um processo permanente e inacabado, fruto das trocas e interações sociais e construída coletivamente. Para ele, é no espaço escolar que aluno e professor aprendem e ensinam mutuamente, a partir de uma relação dialógica do processo educativo e comunicativo. "É preciso, sobretudo, e aí já vai um destes saberes indispensáveis, que o formando, desde o princípio mesmo de sua experiência formadora, assumindo-se como sujeito também da produção do saber, se convença definitivamente de que ensinar não é transferir conhecimento, mas criar as possibilidades para a sua produção ou a sua construção" (FREIRE, 1996, p.22).

Também é preciso refletir que a comunicação, ou, construção e socialização do conhecimento, não pode ser uma metodologia educativa impositiva, como aponta Freire, ao denominar esta prática como educação bancária, onde o sujeito detentor do conhecimento apenas deposita sua leitura subjetiva do conteúdo e contexto, sem abertura para o diálogo. Se desta maneira for, a comunicação torna-se inexiste, com ruídos e limitações em seu processo. A interface comunicação e educação é uma práxis social, uma prática de cidadania, que pode emancipar processos educacionais. 
Por isso, há muitos anos, teóricos de várias partes do mundo buscam apresentar novos paradigmas discursivos transversos que apontam para convergência destes campos. São exemplos como o do educador francês, Celéstin Freinet, que trabalhou junto a seus alunos a produção do jornal em sala de aula, na década de 30, experimentando, além dos benefícios de integração e autonomia resultantes deste processo da produção, a educação para os meios (leitura crítica da mídia). Mário Káplun, uruguaio, tornou-se referência em pesquisas no mundo da educação na América Latina, quando criou, em seu país, na década de 60, um fenômeno chamado Kassete Fórum (fitas kassetes, com aulas gravadas, que eram distribuídas em várias regiões pobres e sem acesso a educação de seu país, reproduzidas em salas comunitárias, principalmente de igrejas, instigando a democratização do conhecimento por meio das mediações tecnológicas predominantes na época).

Paulo Freire, um dos pioneiros na inter-relação comunicação/educação no cenário latino americano e considerado hoje o Patrono da Educação Brasileira, no clássico texto Extensão ou comunicação?, focaliza os processos comunicacionais que se inserem no agir pedagógico libertador; e, é dele, a principal contribuição para que, mais tarde, já nos anos 90, pesquisadores brasileiros atuassem na imersão de estudos de uma nova teoria denominada Educomunicação, que observaremos mais a seguir.

O fato é que, com o advento da democratização da internet, com a necessidade de modernização do sistema pedagógico, com o surgimento constante de novas mídias interativas, com os apontamentos da nova Lei de Diretrizes e Bases - que prevê métodos e procedimentos para formar a competência comunicativa dos educandos, sob os nortes dos estudos das linguagens, códigos e tecnologias -, os questionamentos oportunos e urgentes se configuram, apontando os seguintes problemas a serem debatidos e equacionados: Como o processo de formação dos professores atua nesta vertente de preparação e realidade situacional contemporânea? Como o currículo pode contemplar esta interface comunicação / educação e usar as ferramentas da comunicação - como o jornal, o rádio, a fotografia, a produção audiovisual, a internet - para ampliar a dinamização do processo de ensino aprendizagem? Como a inserção das metodologias de 
comunicação pode ampliar os ecossistemas comunicacionais entre professor e aluno, e entre estes e os demais atores sociais da escola, resultando numa emancipação dialógica que construa sentidos e significados, protagonismos e descobertas, na comunidade escolar?

\section{Promovendo Ecossistemas Comunicacionais}

Os campos da comunicação e da educação são áreas do saber complementares e, ao mesmo tempo, antagônicas. Elas foram criadas com singularidades, se configuram como fenômenos distintos; mas, na prática social se interconectam, se articulam, educam e comunicam. De acordo com Ismar de Oliveira Soares, "efetivamente já se formou, conquistou autonomia e encontra-se em franco processo de consolidação um novo campo de intervenção social a que denominamos de inter-relação comunicação/ educação (SOARES). Esta ação estratégica de interface, ou simplesmente, Educomunicação, não se configura como uma disciplina nova na grade curricular.

Mas uma compreensão de que está sendo inaugurado um novo paradigma constituído por conceitos interdisplinares, comungando e respeitando a presença de contribuições de áreas como a filosofia, a sociologia, antropologia, as artes, história, os estudos das linguagens, entre outras. Este diálogo multivocal, com vários discursos, cujo seu elemento estruturante é a polifonia, garante a sobrevivência deste novo campo educomunicativo que se materializa em algumas áreas de intervenção: a educação para os meios, a gestão da comunicação na escola, as mediações tecnológicas, a reflexão epistemológica.

Já não se pode mais negar que as aproximações entre as práticas educativas e os processos comunicativos estreitaram-se, consideravelmente, no mundo contemporâneo. Há um embate entre as tradicionais agências de socialização escola, família, sociedade - na afirmação dos papéis de protagonismo do processo de formação e consolidação cultural. O problema é que, além desses, há uma outra poderosa agência de socialização que, a cada dia, acaba tornandoa mais protagonista neste processo de formação humana: a mídia. No senso comum, o professor entra na sala de aula com o tradicional plano pedagógico e 
enfrenta um público-alvo pós-moderno, envolto às novas tecnologias e a uma nova cultura de absorção de informações e conhecimentos.

São jovens consumidores de mídia, durante todo o dia, seja pela televisão, pelo jornal, pela emissora de rádio, pela internet ou pelos aplicativos de socialização como o Facebook, WhatsApp, Instagram, Youtube, entre outros. O aluno, público-alvo da escola, entra do portão para dentro, detentor de habilidades midiáticas. Ele sabe criar uma rede social, montar um jogo eletrônico, tratar imagens, produzir um "esqueleto diagramático de um produto de jornal", consegue até editar um vídeo pelo computador ou, até mesmo, pelo celular. $\mathrm{O}$ público-alvo da escola é pós-moderno, porque da porta para fora, o novo mundo educativo exige e incentiva essas novas aquisições de conhecimentos. E eles - os alunos - são rápidos nessas absorções.

Como a escola e o professor estão preparados (ou preparando-se) para lidar com essa situação e mediar todo este processo educativo? Essa questão justifica parte do porquê da necessidade dos professores ampliarem habilidades e da academia redirecionar a ótica dos planos de formação dos futuros professores e das pesquisas nesse norte. Outra questão importante: Se as produções de conteúdos das mídias estão sendo cada vez mais facilmente absorvidas pelos atores sociais que permeiam pela escola, como os professores podem atuar, auxiliando na educação para/pelo/com os meios (leitura crítica), ou seja, na filtragem e debate sobre essas produções, já que o conteúdo midiático absorvido é, quase sempre, conteúdo ausente de pluralidade e diversidade - característica da mídia de massa?

Se parece um embate desleal - observação refletida por muitos autores - na percepção cultural dos sentidos e dos valores, por que também não produzir e usar as ferramentas da comunicação como o rádio, o jornal, a internet, a fotografia e o audiovisual para dinamizar o processo de ensino-aprendizagem? Essas mídias instigam a criatividade no processo de produção, ampliam a socialização, a dinâmica e o desenvolvimento de novas habilidades. 
Além disso - e fundamentalmente - nos seus processos de formação, os professores não são formados para entender como decodificar esses mecanismos de construção da informação e o uso das ferramentas das mídias, nem tampouco, em como trabalhar uma pedagogia voltada para a produção, para a educação para os meios e para o uso dessas ferramentas como alternativas pedagógicas. De um lado, muitos pesquisadores, há muito tempo, defendem a importância dessa interface e propõem reflexões e atividades pedagógicas que dinamizam o processo de ensino-aprendizagem; do outro lado, há pesquisadores que tecem críticas à improdutividade desses conteúdos e ferramentas de mídia para a escola. Esse conflito, para muitos pesquisadores, é fruto de preconceito e não entendimento do avanço pós-moderno em que o sistema educacional vivencia.

Esta realidade pós moderna da comunicação os levam a uma empatia cognitiva e expressiva com estas novas tecnologias, percebendo com outra ótica o espaço e o tempo, a velocidade e a lentidão, o próximo e o distante. É uma experiência cultural nova. Um sensorium novo que, muitas vezes, se choca com o sensorium dos adultos. Quando acontece, os jovens alunos passam a perceber muito claramente que, em muitos casos, do portão para dentro, a escola está descontextualizada do mundo externo. É como se a escola fosse um outro mundo, que tem dificuldade de trabalhar - com práticas e mecanismos atrativos que aproximem da realidade de interesse dos alunos - esta ansiedade e imediatismo característico deste novo formato de absorção de informações que os jovens vivenciam hoje.

Está, ai, o desafio e o embrião desta reflexão científica. Assim como Mário Kaplúm percebeu a urgência social e cultural de usar as ferramentas tecnológicas da época (uma fita cassete) para facilitar o encaminhamento das informações e democratizar conhecimentos, hoje, percebe-se que não tem como correr deste avanço pós moderno que as ferramentas da comunicação propiciam no contexto da construção subjetiva do conhecimento. Kaplúm usou as ferramentas. Mas Freire enalteceu que o processo dialógico enriquece a subjetividade humana, por isso, era preciso haver alianças e embates subjetivos. Soares ressignificou estes contextos e nos possibilitou a compreensão da 
educomunicação, a partir da compreensão da importância do uso das produções de comunicação em sala de aula, aliado aos conteúdos curriculares, como forma de ampliar, dinamizar e enriquecer o ecossistema comunicacional.

\section{Professor, ator social em transformação}

O professor é mais do que um ator social simbólico. É um agente político transformador. Mas não é difícil encontrar professores que tenham dificuldades de acessar um computador, de criar uma rede social ou um blog, de produzir um jornal em sala de aula, que saiba operar uma máquina fotográfica, ou até mesmo de montar um grupo de pesquisa pelo celular. Não é difícil encontrar escolas que mantém fechado a sala de informática, não apenas por questões de segurança ou por algum problema técnico, mas, também, por que falta habilidade ao professor para mediar conhecimentos naquele ambiente. $\mathrm{E}$ isso não é culpa dos professores. Muitos processos de formação de professores não contemplavam esta realidade - e muitos ainda não contemplam -. Também falta política pública efetiva que invista em capacitação continuada, em infraestrutura, e possibilite ao professor esta interação com as múltiplas ferramentas da comunicação.

Importante enaltecer que não trata-se, apenas, do uso das ferramentas da comunicação em sala de aula, mas, de capacitar os professores - das múltiplas áreas - para que seus projetos pedagógicos, quando abastecidos com estas ferramentas, sejam norteados pelo enriquecimento do ecossistema comunicacional nestes cenários onde estão inseridos - este é principal ponto de reflexão. Este coeficiente comunicacional enriquecido é o que harmonizará as relações dialógicas, fluindo melhor os conhecimentos e o desenvolvimento das habilidades. Por exemplo: um projeto de uma Rádio Escola, além de ensinar a manusear uma mesa e uma caixa de som, um microfone, um computador, também promove a reunião de pauta prévia entre os alunos, a escolha-estudoprodução dos temas que serão abordados, a arte do cenário, a música que embalará, a escrita dos textos informativos, a socialização e o diálogo, a dinamização na transmissão do conteúdo programático estabelecido, a 
observação crítica, a curiosidade instigada, o registro, o sorriso do protagonismo, a inspiração e o desejo da próxima edição.

Educar o olhar num projeto de fotografia na escola pode trabalhar a estética e leitura dos signos e significados dos ambientes sociais onde os alunos estão inseridos, instigar abordagens de reflexão crítica e construção de realidades, trabalhar técnicas de produção de arte sob o norte de conteúdos programáticos estabelecidos, promover exposições e instigar a socialização, entre outros benefícios. Produzir um jornal em sala de aula, um fanzine - feito na folha de sulfite -, ou, um Jornal Mural, trabalha a leitura crítica da mídia, explicita as técnicas e produção da construção da informação - que é específica. Mobiliza o debate e a organização nas reuniões de pautas - sobre o que os alunos abordarão naquela edição -, trabalha a ilustração fotográfica, instiga a correta produção da escrita, mobiliza o espírito de protagonismo e de responsabilidade social e cultural, senso político e de liderança, trabalha a produção editorial, a estrutura diagramática / layout no computador. Atua no enriquecimento da socialização, integração. Estas são só algumas das experiências de educomunicação possíveis.

A academia, com pesquisas e disciplinas que abordem a gestão da comunicação, as mediações tecnológicas, a educação para os meios, nos cursos de graduação dos educadores; a gestão pública, com projetos, cursos, debates, oficinas e workshops de formação continuada nesta interface comunicação/ educação; a mídia clássica (TV, rádio, jornal, portais de notícias), divulgando os trabalhos dos professores e das escolas neste norte de modernização do sistema - e participando de ações -, consolidariam um pacto de forças possível para realinhar as interfaces do conhecimento - sem deslocar as peculiaridades de cada uma destas agências de socialização. Mas cabe ao professor, a boniteza do ato de transformar.

\section{O aporte epistemológico}

Vários importantes autores analisam e discutem questões sobre os espaços de debates e construções acerca da intersecção comunicação/educação, a educomunicação, e suas relações com os processos de formação dos professores 
neste vertente. Nessa perspectiva, a contribuição de autores como Freire (1971;1996), Kaplún (1998), Soares (1999; 2002), Vygotsky (1991),Baccega (2000) e Citelli (1999) e Orofino (2005) tornam-se fundamentais, pois trazem luz para entender questões e formular perspectivas reflexivas sobre a realidade situacional da educação frente aos novos discursos educativos, pautados pelo viés das novas tecnologias, que passaram a se constituir na nova sociedade educativa.

Orofino (2005) destaca a influência e abrangência da mídia na escola, já que os vínculos entre as práticas educativas e os processos comunicativos aproximaram-se. Entende-se que a instituição escola, enquanto ambiente formal de aquisição e produção de cultura e aprendizagem, ainda possui resistência em alguns conteúdos que afirmam essa interface.

[...] a TV e o rádio cobrem 98\% do território brasileiro, levando informação, entretenimento, valores éticos e políticos aos mais distantes recantos do país. Portanto, não há escola, por mais distante e diversa que seja, queconviva sem a presença de alguma influência da cultura das mídias (OROFINO, 2005, p. 40).

Freire, uma das principais referências nos estudos sobre processos dialógicos e educação libertária, analisa, em suas obras, que o diálogo enriquecido é o cerne de todo processo de construção subjetiva, respeitando as particularidades sociais, culturais, políticas que cada sujeito tem, promovendo, assim, embates subjetivos que possibilitam a construção democrática do saber. A educação, segundo Freire (1971, p. 69): “é comunicação, é diálogo, na medida em que não é transferência de saber, mais um encontro de sujeitos interlocutores que buscam a significação dos significados”.

Em Pedagogia da Autonomia, Freire (1996) faz indagações referentes a essa nova cultura de aprendizagem que faz com que professores discutam com seus alunos a realidade concreta a que se deva associar a disciplina cujo conteúdo se ensina. Freire indaga:

Por que não discutir as implicações políticas e ideológicas de um tal descaso dos dominantes pelas áreas pobres da cidade? A ética da classe embutida neste descaso? Porque, dirá um educador reacionariamente pragmático, a escola não tem nada a ver com isso. A escola não é partido. Ela tem que ensinar os 
conteúdos, transferi-los aos alunos. Aprendidos, estes operam por si mesmos(p. 30-31).

Para compreender essa evolução seguida de todas as dificuldades relativas à aprendizagem, seja como alunos ou como professores, é necessário começar por situar essas atividades no contexto social em que são geradas. Em Pedagogia da Autonomia, Freire defende que é preciso, sobretudo, que o formando, desde o princípio mesmo de sua experiência formadora, assumindo-se como sujeito também na produção do saber, se convença definitivamente de que ensinar não é transferir conhecimento, mas criar as possibilidades para a sua produção ou a sua construção.

Kaplún (2010) nos possibilita, com sua visão progressista, refletir sobre a educação permeada pelas metodologias dinâmicas, inter-relacionadas com a ampliação dialógica e as novas tecnologias, especialmente, o uso do rádio como ferramenta educativa. Suas leituras de mundo e de educação transformadora demonstram, com suas experiências, aproximações com as ideias freireanas. A pesquisa também pretende visitar a literatura do psicólogo e linguista russo Lev Vygotsky (1991), que também permeia pela educação pautada na ampliação do coeficiente comunicacional. Ele aprofunda o conceito de aprendizagem como processo social, enquanto o sujeito aprende na interação com o outro.

A partir dessas reflexões que pairam sobre a comunicação enquanto essência de democratização dialógica, emancipação de sujeitos e de processos de transformação dos cenários educativos, a pesquisa emerge nas reflexões que dão aporte à teoria da Educomunicação, uma área do conhecimento, construída na Escola de Comunicação e Artes da Universidade de São Paulo (ECA - USP) e que há mais de 20 anos se perpetua como alternativa para compreensão: 01) dos efeitos da interface comunicação e educação na perspectiva da gestão da comunicação na escola (e/ou outros espaços de troca de saber); 02) na educação para os meios (ampliação da leitura e consciência crítica frente aos meios de comunicação); 03) na mediação tecnológica (o uso das ferramentas da tecnologia de comunicação na escola) e 04) nas reflexões epistemológicas (área de contextualização dos processos e produção científica). Para compreender esta teoria e associar com a formação do professor para o melhor uso da 
comunicação e das tecnologias dentro da sala de aula, emprestamos as contribuições de Soares (1999; 2002). O autor define a Educomunicação como:

O conjunto das ações inerentes ao planejamento, implementação e avaliação de processos, programas e produtos destinados a criar e fortalecer ecossistemas comunicativos em espaços educativos presenciais ou virtuais, assim como a melhorar o coeficiente comunicativo das ações educativas, incluindo as relacionadas ao uso dos recursos da informação no processo de aprendizagem (SOARES, 2002, p. 115).

Baccega (2000) alerta que as tradicionais agências de socialização - escola e família -vêm se confrontando, nos últimos tempos, com os meios de comunicação, que se constituem em outra agência de socialização. Ela enaltece que existe, neste meio, um embate constante, uma disputa, pela hegemonia na formação dos valores dos sujeitos, na configuração dos sentidos sociais. Outra contribuição importante inserida neste projeto de pesquisa é do professor Adilson Citelli (1999). Em suas reflexões, ele propõe alternativas para atividades educativas a partir das linguagens dos meios de comunicação e das novas tecnologias. 


\section{Referências}

BACCEGA, Maria Aparecida. Televisão e escola: uma mediação possível? São Paulo: Editora SENAC São Paulo, 2000.

CITELLI, Adilson. Comunicação e Educação. A linguagem em Movimento.

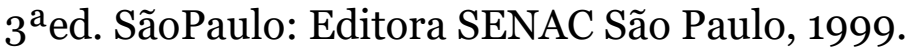

FREIRE, Paulo. Extensão ou comunicação? Rio de Janeiro: Paz e Terra, 1971.

FREIRE, Paulo.

Pedagogia da Autonomia: saberes necessários à pratica docente. Rio de Janeiro: Ed. Paz e Terra, 1996.

INEP, Portal: Inep divulga dados inéditos sobre fluxo escolar na educação básica. 20 jun. 2017. Notícias. Disponível em:

http://portal.inep.gov.br/web/guest/resultados-e-resumos. Acesso em 23 abr. 2019.

KAPLÚN, Mario. Una pedagogía de la comunicación. Madrid: Ediciones de la Torre, 2010.

NEALDO, Carlos. Número de matrículas na educação básica de Alagoas recua 17,4\% em 2018, diz Inep. Gazeta Web Notícias, Alagoas, 01 fev. 2019.

Disponível em: https://gazetaweb.globo.com/portal/noticia/2019/o2/numerode-matriculas-na-educacao-basica-de-alagoas-recua-174-em-2018-dizinep 69345.php. Acesso em: 22 abr. 2019.

OROFINO, Maria Isabel. Mídias e Mediação Escolar: pedagogia dos meios, participação e visibilidade. São Paulo: Cortez, 2005.

SOARES, Ismar de Oliveira. Metodologias da Educação para Comunicação e Gestão Comunicativa no Brasil e na América Latina. In: BACCEGA, Maria Aparecida (org.). Gestão de Processos Comunicacionais. São Paulo: Atlas, 2002.

SOARES, Ismar de Oliveira. Comunicação/Educação: A emergência de um novo campo e o perfil de seus profissionais. In: Contrato. Brasília, ano 1, n.2, jan/mar 1999, p. 19-74.

VYGOTSKY, L.S. Pensamento e Linguagem. São Paulo: Martins Fontes, 1991. 